\title{
Social participation reduces depressive symptoms among older adults: An 18-year longitudinal analysis in Taiwan
}

\author{
Chi Chiao ${ }^{1 *}$, Li-Jen Weng ${ }^{2}$ and Amanda L Botticello ${ }^{3}$
}

\begin{abstract}
Background: Relatively little empirical attention has focused on the association between social participation and depressive symptoms amongst older adults in Asian nations, where persons over the age of 65 represent a rapidly growing segment of the population. This study explores the dynamic relationship between participation in social activities and trajectories of depressive symptomatology among older Taiwanese adults surveyed over 18 years.

Methods: Data are from a nationally representative sample of 1,388 adults aged 60-64 first surveyed in 1989 and followed over an 18-year time period for a total of six waves. Individual involvement in social activities was categorized into continuous participation, ceased participation before age 70, initiating participation in older adulthood, never participated, and dropped out before age 70. Two domains of depressive symptoms-negative affect and lack of positive affect-were measured using a 10-item version of the Center for Epidemiologic StudiesDepression Scale.

Results: Analyses using growth curve modeling showed that continuously participating or initiating participation in social activities later life is significantly associated with fewer depressive symptoms among older Taiwanese adults, even after controlling for the confounding effects of aging, individual demographic differences, and health status.

Conclusions: These findings suggest that maintaining or initiating social participation in later life benefits the mental health of older adults. Facilitating social activities among older adults is a promising direction for programs intended to promote mental health and successful aging among older adults in Taiwan.
\end{abstract}

Keywords: Depressive symptoms Social participation, Older adults, Growth curve modeling, Taiwan

\section{Background}

Depression is one of the most common chronic mental health conditions among older adults in Chinese communities $[1,2]$. Symptoms of depression experienced in later life have serious implications for the health and functioning of older persons as emotional distress is consistently associated with higher levels of cognitive $[3,4]$ and functional impairment $[5,6]$, and the increased risk of physical illnesses such as heart disease and stroke. Depressive symptoms also place older adults at

\footnotetext{
* Correspondence: cchiao@ym.edu.tw

${ }^{1}$ Insitute of Health and Welfare Policy, Research Center for Health and Welfare Policy, School of Medicine, National Yang-Ming University, Taipei, Taiwan, China

Full list of author information is available at the end of the article
}

the increased risk for suicide [7-10], which can devastate families and communities.

Growing evidence suggests that involvement in social activities improves the mental health of older adults. Research has demonstrated that socially active older adults have better health outcomes than their inactive counterparts, such as lower mortality rates [11,12], better physical functioning [13], and higher cognitive functioning [14,15]. Work in this area suggests that participation in social activities provides older adults with social support from informal social networks (i.e., relationships with other social group members and peers), which in turn benefits their emotional functioning $[16,17]$.

Prior studies examining the relationship between social participation and mental health also suggest that various

\section{Biomed Central}


forms of social participation have psychological advantages for older adults. For example, religious participation [18] and volunteer work [19] increased individual social resources (measured by meeting attendance and informal social interaction), which, in turn, lowered depressive symptom levels. Research by Li and Ferraro [20], Musick and Wilson (2003) [19], and Thoits and Hewitt (2001) [21] used longitudinal data from the Americans' Changing Lives study to explore the relationship between volunteering and depressive symptoms among older adults. These analyses each suggested that older adults psychologically benefited from sustained volunteering. Sugihara et al (2008) [22] examined the role of social participation in mitigating psychological distress in a nationally representative sample of Japanese adults aged 55 to 64 . They found that volunteer work was significantly associated with fewer depressive symptoms for both males and females. Although these studies involved analysis of longitudinal data and identified a relationship between a particular type of social participation and mental health, one of the outstanding questions raised by prior investigations was how change and duration of social participation affected the development of psychological distress in later life. That is, variations in exposure to a protective resource-such as the continuity, initiation, or cessation of social participation-may differentially increase or decrease the likelihood of experiencing psychological distress among older adults [23].

This study seeks to increase our understanding of the complex association between social participation and depressive symptoms by analyzing this relationship from a lifecourse perspective. Our analysis uses a nationally representative sample of older adults from Taiwan, as Asian nations are less frequently the focus of empirical investigations of protective effects in mental health outcomes.

\section{Methods}

\section{Sample and Data Collection}

This study uses data collected from the Taiwan Longitudinal Study on Aging (TLSA), a nationally representative survey designed to study the impact of socioeconomic development on physical and emotional well-being of the older adult population in Taiwan. This prospective, longitudinal study involved data collection from 1989 to 2007 for a total of six waves. Detailed information on the study methodology and TLSA data collection is provided by the Bureau of Health Promotion at the Department of Health in Taiwan http://www.bhp.doh.gov.tw. The sample was derived with a multi-stage sampling framework. First, a total of 56 neighborhoods-defined as blocks or lins-were selected from nationwide administrative units. Second, individual persons aged 60 and older were selected within blocks, yielding the total original sample of $\mathrm{N}=4,049$. Participants were administered structured questionnaires in their homes by trained interviewers at baseline (1989), with follow-up surveys administered in 1993, 1996, 1999, 2003 and 2007. The response rates were $92 \%, 91 \%, 89 \%, 90 \%, 91 \%$ and $91 \%$ for each wave of data collection [24].

The analytic sample used for this study was restricted to those participants in the 60-64 year old age group at the baseline with complete data on the short form (10 items) of the Center of Epidemiological Studies-Depression scale from at least one follow-up. Our selection of this age group was based on three substantive considerations. First, this age group was not officially retired at baseline, which allowed us to examine changes in the relationship between participation and the distress both before and after retirement. Second, the life expectancy in 1989 in Taiwan was 71 years for males and 76 years for females [25]. As this study was based on the lifecourse perspective, we chose to examine the age group that was likely to survive for a large portion of the 18year study. Thirdly, the age of 70 also provided a point of reference prior to the period of the lifecourse when we expected the risk for morbidity and mortality in our sample to increase. This selection yielded a final analytic sample of 1,388 older adults aged 60-64 years at the baseline, 1,174 in 1993, 1,047 in 1996, 960 in 1999, 800 in 2003, and 601 in 2007.

Study attrition over time was experienced in part due to longitudinal study design and the older adult sample. We assessed differences in social participation and individual characteristics between continuing participants and those participants that were lost to follow-up (the results not tabled). The analyses indicated that continuing participants at the sixth wave were significantly more likely to initiate participation in social activities in later life $(\mathrm{OR}=1.43, p<0.05)$ and had less physical limitations $(\mathrm{OR}=0.61, p<0.001)$ in comparison to the group that was lost to follow-up. The decline in sample size was primarily due to death.

\section{Measures}

\section{Dependent variable}

Depressive symptomatology was measured by a 10 -item version of the Center of Epidemiological StudiesDepression (CES-D) scale at each wave of the TLSA survey. The original 20-item CES-D [26] has been widely used in survey research to assess emotional distress in the general population, and has been demonstrated to have good validity and reliability when used with Asian populations [27-30]. Each of the 10 items was rated on a four-point scale (scored 0-3), indicating the frequency of experiencing each symptom in the past week. Responses were reversely scored when necessary such that higher scores represented greater levels of 
symptom frequency. Based on prior analyses using this sample [30-32], two factors were identified from the 10 CES-D items: a negative affect domain and a lack of positive affect domain. These CES-D items adopted in TLSA across waves are listed in the Appendix. More detailed information on psychometric properties of these two domains could be found in Chiao et al (2009) [29]. For the analysis, the items were summed within the two domains. The total score on the negative affect domain ranged from 0 to 24 with good internal consistency and reliability ( $\alpha$ ranging from $0.79-0.87$ across waves). The total score on the lack of positive affect domain ranged from 0 to 6 with an internal consistency reliability coefficient $\alpha$ of 0.79-0.95 across the waves.

\section{Explanatory variable}

Social participation was operationalized using items that measured social engagement. Participants reported whether they participated in group activities through any one of six types of social organizations: hobbyrelated clubs, religious or church groups, political groups, retired or elderly-related associations, or volunteer groups. For each type of social activity, older adults were further asked how long they had participated in an organization at each wave. As the objective of this study was to assess the potential dynamics between participation in social activities and distress during older adulthood over time, we used both participation in least one activity and participation duration to construct a measure of participation continuity by age of 70 using survey information from wave 1 to 3 . The final social participation variable consists of the following five categories: (1) continuous social participation (from baseline to age 70 ); (2) ceased participation in older adulthood (between baseline and age 70); (3) initiating participation in older adulthood (after baseline); (4) never participated; and (5) dropped out before age 70.

\section{Covariates}

Age was included in all growth curve analyses as the time-varying covariate to assess change over time in depressive symptoms over the 18 -year period. The relationship between aging and depressive symptoms has been reported as linear with a minor curvilinear effect [31]. Prior research has documented a robust association between physical limitations, chronic illness, and the mental health of older adults [33]. Therefore, indicators of physical health were assessed as covariates and measured by the presence or absence of physical disability and chronic illness, respectively. Physical disability was assessed from eight ADLs and IADLs items. The disability items assessed a person's difficulty with crouching, standing, stooping, lifting heavy objects, walking, climbing stairs, grasping small objects with their fingers, and taking a bus alone. We dichotomized disability status into those with no functional problems (coded " 0 ") and those with at least one limitation (coded "1") following an approach used frequently in prior studies [34-37]. Chronic illness was assessed as a dichotomous measure $(0=$ no; $1=$ yes $)$ indicating whether respondents had medical diagnosis of at least one of the following five health problems: hypertension, diabetes, stroke, respiratory disease, and cardiovascular disease. Both disability and chronic illness status were based on health status reported at baseline.

The socio-demographic variables included gender and ethnicity. Ethnicity was categorized as Fukianese, Hakka, and Mainlander (i.e., individuals who fled the communist government of the People of Republic of China). Socioeconomic status (SES) was assessed by measures of education, employment status, and home ownership. The presence of family members in the immediate environment can be a source of both stress and social support for older adults $[38,39]$ and is also an important feature of Taiwanese and Asian societies. Therefore, family living arrangements was included in the analysis and it was divided into two categories: living alone and living with extended family members. All sociodemographic indicators were based on measures obtained at baseline.

\section{Analytic Strategy}

All analyses were conducted using STATA [40]. Sampling weights and statistical procedures with robust standard errors were also used throughout the analyses to correct for any potential biases. Bivariate tests (i.e., ANOVA and Bonferroni post hoc tests) were used to assess differences in the distribution of individual characteristics by types of social participation. Growth models calculated using the gllamm commands in STATA, were used to model depressive trajectories over the six waves of the study separately for the negative affect domain and the lack of positive affect domain. Twolevel growth models were specified with individuals at level 2 and age at level 1 [41].

We used a sequential modeling strategy for the multivariate portion of the analysis, progressively adjusting our growth curve models to assess the relationship between social participation and change in depressive symptoms over time. The first model included individual social participation and age to examine whether there was significant variability in depressive symptoms over time for different categories of social participation. As suggested by prior research [31], the longitudinal relationship between aging and depressive symptoms is non-linear for Taiwanese older adults, and therefore we included a quadratic term in all growth curve models. The second model then added individual baseline controls (including health conditions, socio-demographic characteristics, and socioeconomic status) to the first model in order to assess the relative effect of social 
participation after adjusting for individual controls. As suggested by previous studies [22], an interaction term for individual social participation by gender was tested in all the models to explore any possible gender differences in depressive symptoms across the different participation categories.

\section{Results}

Table 1 summarizes the distributions of individual characteristics stratified by categories of social participation. Approximately two-thirds of the sample reported no physical disability at baseline. Bivariate tests indicated that older adults who had better physical health status were more likely to be represented among the group that reported continuous social participation before age 70 (by wave 3) (71\%) in contrast with $59 \%$ group who reported never participating and $57 \%$ of the group lost to follow-up. A relatively small portion of the sample (17\%) reported experiencing chronic illness at baseline; unsurprisingly, persons with chronic illness were disproportionately represented among the group lost to follow-up midway through the TSLA data collection (i.e., by the age of 70). Due to a large number of male migrants from China in 1949 , males comprised the majority of the sample (63.33\%), and as expected, males and females exhibited significantly different patterns of participation in later life. We also observed significant differences in patterns of social participation by ethnicity, education level, work status, homeownership, and family living arrangement, as reported on Table 1. The continuous group reported lower levels of depressive symptoms on both domains in comparison to the never participated group and the dropped-out group.

Table 2 presents the results of the growth curve analysis for the negative affect domain. Model 1 shows a significant effect of social participation on negative affect, independent of aging. In comparison to those who never participated in social activities, persons who continued or initiated their social participation as older adults have a significantly lower level of depressive symptoms $\left(\beta_{01}=-1.41, p<0.001\right.$ and $\beta_{02}=-1.13, p<$ 0.001 respectively) over time. We also observed a modest negative association between participation and negative affect over time $\left(\beta_{03}=-0.71, p<0.05\right)$ for those who ceased participation before age 70 , suggesting that even unsustained social activity (as compared to no involvement) in older adulthood is psychologically beneficial in the long term. As for the aging effect, levels of depressive symptoms on the negative affect domain increased with age (mean linear growth rate $=0.18, p<0.001$ ) with the acceleration in the likelihood of symptoms diminishing slightly over time (mean quadric growth rate $=-0.004, p<0.01$ ).
In order to assess the effects of confounding factors, the individual covariates were included in subsequent models. Although though the coefficients for those who continued or initiated their social participation remain significant, the magnitude of these associations was appreciably reduced after adjusting for individual differences in health status (i.e., presence of disability or chronic illness) socio-demographic characteristics, and socioeconomic status. The observed relationship between participation and negative affect for the group who ceased participation was rendered non-significant when health and socio-demographic differences were taken into account. Experiencing physical disability increased the level of negative affect over time. Conversely, the level of negative affect decreased with higher education attainment, with full- or part-time employment (versus not employed), with home ownership (versus not), and with living with family members (versus living alone). Contingencies between gender and social participation were found to be non-significant (model not tabled), suggesting that the protective effect of social participation on negative affect did not differ between men and women.

Table 3 presents the results for the lack of positive affect domain. Model 1 showed that the likelihood for a lack of positive affect was decreased by either continued or initiated social participation in older adulthood $\left(\beta_{01}=\right.$ -0.74, $p<0.001$ and $\beta_{02}=-0.48, p<0.001$ respectively), as compared to never participating. We also observed a modest negative relationship among those individuals who ceased participation in older adulthood; as before, this suggests that some participation in social activities in later life is better than nothing at all. The overall relationship between social participation and lack of positive affect persisted even after adjusting for individual differences (Model 2). As with the negative affect domain, presence of a disability increased the tendency to experience a lack of positive affect over time and slightly attenuated some of the psychological benefit of participation on long-term depressive symptomatology. Our results demonstrated that lack of positive affect decreased with age, suggesting that this aspect of depressive symptomatology changes, at least in part, with the passage of time.

\section{Discussion}

This study suggests that overall, social participation benefits the mental health of older Taiwanese adults. Our analysis also illustrates the dynamic nature of this relationship; that is, our results demonstrate that social involvement that is continued or initiated in later life is protective of mental health over and above individual differences in social circumstances and health status. However, our observation of a modest effect for 
Table 1 Sample characteristics [mean (SD) or percent] by categories of social participation at the 1989 baseline interviews in the Taiwan Longitudinal Study on Aging (TLSA)

\begin{tabular}{|c|c|c|c|c|c|c|}
\hline & $\begin{array}{l}\text { Continuous participation } \\
\text { from baseline to age } 70 \\
\qquad(n=259)\end{array}$ & $\begin{array}{l}\text { Initiating participation } \\
\text { from baseline to age } 70\end{array}$ & $\begin{array}{l}\text { Ceased } \\
\text { participation after } \\
\text { baseline } \\
\quad(n=200)\end{array}$ & $\begin{array}{c}\text { Never } \\
\text { participated } \\
\text { before age } \\
70 \\
(n=359)\end{array}$ & $\begin{array}{l}\text { Dropped } \\
\text { out } \\
\text { before } \\
\text { age } 70 \\
(n=296)\end{array}$ & $\begin{array}{c}(n= \\
1,388)\end{array}$ \\
\hline \multicolumn{7}{|l|}{ Health status } \\
\hline $\begin{array}{l}\text { Physical disability: One and } \\
\text { more functioning limitations } \\
\text { (\%) }\end{array}$ & $28.57^{b}$ & 33.94 & 33.50 & $40.67^{\mathrm{a}}$ & $42.91^{\mathrm{ab} * *}$ & 36.53 \\
\hline $\begin{array}{l}\text { Chronic disease: One and more } \\
\text { chronic conditions (\%) }\end{array}$ & 15.83 & $13.50^{\mathrm{a}}$ & 17.00 & 14.76 & $22.64^{\mathrm{a} *}$ & 16.71 \\
\hline \multicolumn{7}{|l|}{$\begin{array}{l}\text { Socio-demographic } \\
\text { characteristics }\end{array}$} \\
\hline Male (\%) & $80.31^{\text {aef }}$ & $57.66^{\mathrm{ceg}}$ & $76.50^{b}$ & $43.73^{\mathrm{abcd}}$ & $68.58^{\mathrm{dfg}} * * *$ & 63.33 \\
\hline \multicolumn{7}{|l|}{ Ethnicity (\%) } \\
\hline Fukianese & $51.35^{\mathrm{a}}$ & $62.77^{c}$ & $47.50^{\mathrm{bc}}$ & $65.74^{\mathrm{ab}}$ & $58.11^{* * *}$ & 58.21 \\
\hline Hakka & 15.06 & 16.06 & 14.00 & 15.32 & 10.14 & 14.12 \\
\hline Mainlander & $33.59^{\mathrm{ad}}$ & $21.17^{\text {def }}$ & $38.50^{\text {be }}$ & $18.94^{\mathrm{abc}}$ & $31.76^{\mathrm{cf***}}$ & 27.67 \\
\hline \multicolumn{7}{|l|}{ Socioeconomic position } \\
\hline \multicolumn{7}{|l|}{ Education (\%) } \\
\hline Illiterate & $17.76^{\mathrm{ad}}$ & $31.02^{d}$ & $19.50^{\mathrm{b}}$ & $38.44^{\mathrm{abc}}$ & $25.68^{\mathrm{C***}}$ & 27.67 \\
\hline $\begin{array}{l}\text { Incomplete primary } \\
\text { education }\end{array}$ & 10.04 & 15.69 & 15.00 & 18.11 & 17.91 & 15.63 \\
\hline $\begin{array}{l}\text { Completed primary } \\
\text { education }\end{array}$ & 36.68 & 33.58 & 34.00 & 27.02 & 28.72 & 31.48 \\
\hline $\begin{array}{l}\text { High school graduate and } \\
\text { above }\end{array}$ & $35.52^{\text {ae }}$ & $19.71^{\text {cef }}$ & $31.50^{\mathrm{bf}}$ & $16.43^{\mathrm{abcd}}$ & $27.70^{d * * *}$ & 25.22 \\
\hline \multicolumn{7}{|l|}{ Work status (\%) } \\
\hline No work & $27.03^{b}$ & $17.15^{\mathrm{ac}}$ & 33.50 & $30.92^{\mathrm{a}}$ & $40.54^{\mathrm{bc}}$ & 29.90 \\
\hline Full- or part-time work & $53.28^{\mathrm{ac}}$ & $51.09^{\mathrm{bd}}$ & 47.00 & $37.05^{\mathrm{ab}}$ & $38.51^{\mathrm{cd} * * *}$ & 44.60 \\
\hline Assisting family & $19.69^{\mathrm{ad}}$ & $31.75 d^{\text {ef }}$ & $19.50^{\text {be }}$ & $32.03^{\mathrm{abc}}$ & $20.95^{\mathrm{cf} * * *}$ & 25.50 \\
\hline Home owned (\%) & $74.52^{b}$ & $78.10^{d}$ & $74.00^{c}$ & $72.70^{\mathrm{a}}$ & $60.14^{\mathrm{abcd} * * *}$ & 71.61 \\
\hline \multicolumn{7}{|l|}{ Family background } \\
\hline Lives with family (\%) & $80.69^{a}$ & $81.75^{b}$ & 74.00 & 73.26 & $64.19^{\mathrm{ab} * * *}$ & 74.50 \\
\hline \multicolumn{7}{|l|}{ CES-D score } \\
\hline Negative affect domain & $\begin{array}{l}2.02^{\text {ad }} \\
(2.94)\end{array}$ & $\begin{array}{l}2.16^{\mathrm{ce}} \\
(3.22)\end{array}$ & $\begin{array}{l}2.54^{b} \\
(3.84)\end{array}$ & $\begin{array}{l}3.55^{\mathrm{abc}} \\
(4.54)\end{array}$ & $\begin{array}{l}3.52^{\text {de**** }} \\
(4.55)\end{array}$ & $\begin{array}{c}2.84 \\
(3.99)\end{array}$ \\
\hline Lack of positive affect domain & $\begin{array}{c}2.63^{\text {acd }} \\
(2.35)\end{array}$ & $\begin{array}{l}3.14^{\mathrm{b}} \\
(2.26)\end{array}$ & $\begin{array}{l}3.51^{\mathrm{c}} \\
(2.32)\end{array}$ & $\begin{array}{l}3.67^{\mathrm{ab}} \\
(2.14)\end{array}$ & $\begin{array}{c}3.53^{\mathrm{d} * * *} \\
(2.18)\end{array}$ & $\begin{array}{l}3.32 \\
(2.27)\end{array}$ \\
\hline
\end{tabular}

${ }^{*} p<0.05 ;{ }^{* *} p<0.01 ;{ }^{* * *} p<0.001$

$a, b, c, d, e, f, g$ Bonferroni post hoc tests: values with identical superscripts differ at the 0.05 level.

those adults who had to cease social participation in their 70's also suggested that some involvement in social activities in later life is better for mental health as compared to no social participation at all. This observed association was accounted for by individual differences - specifically, physical disability - suggesting that functional impairments are a major threat to social activity later in life.
This study adds to the body of research showing the benefits of remaining socially active in later life, as demonstrated by lower depressive symptom levels for adults who reported continued involvement in social activities versus adults who reported no social participation. As suggested by our analyses, making a continuous effort to participate in social activities in late life is a commitment to preserving the older person's mental 
Table 2 Growth curve models predicting depressive symptomatology on the negative affect domain, the Taiwan Longitudinal Study on Aging (TLSA) 1989-2007

\begin{tabular}{|c|c|c|c|c|}
\hline \multirow[b]{2}{*}{ Covariates } & \multicolumn{2}{|c|}{ Model 1} & \multicolumn{2}{|c|}{ Model 2} \\
\hline & Coefficient $(\beta)$ & Standard Error & Coefficient $(\beta)$ & Standard Error \\
\hline \multicolumn{5}{|l|}{ Social participation } \\
\hline \multicolumn{5}{|l|}{ Participation before 70 (ref = never participated) } \\
\hline Continuous participation from baseline to age $70, \beta_{01}$ & $-1.414^{* * *}$ & 0.262 & $-0.681^{* *}$ & 0.250 \\
\hline Initiating participation from baseline to age $70, \beta_{02}$ & $-1.128^{* * *}$ & 0.256 & $-0.709^{* *}$ & 0.235 \\
\hline Ceased participation after baseline, $\beta_{03}$ & $-0.710^{* * *}$ & 0.283 & $-0.195^{* *}$ & 0.265 \\
\hline Dropped out before age $70, \beta_{04}$ & $0.003^{* *}$ & 0.277 & $0.111^{* *}$ & 0.262 \\
\hline \multicolumn{5}{|l|}{ Health status } \\
\hline \multicolumn{5}{|l|}{ Physical disability (ref = None) } \\
\hline One and more functioning limitations & & & $1.789^{* * *}$ & 0.180 \\
\hline \multicolumn{5}{|l|}{ Chronic health problems (ref = None) } \\
\hline One and more chronic conditions & & & $-0.297^{* * *}$ & 0.221 \\
\hline \multicolumn{5}{|l|}{ Socio-demographics } \\
\hline \multicolumn{5}{|l|}{ Gender (ref = Male) } \\
\hline Female & & & $0.294^{* * *}$ & 0.221 \\
\hline \multicolumn{5}{|l|}{ Ethnicity (ref = Fukianese) } \\
\hline Hakka & & & $0.017^{* * *}$ & 0.240 \\
\hline Mainlander & & & $-0.122^{* * *}$ & 0.218 \\
\hline \multicolumn{5}{|l|}{ Socioeconomic position } \\
\hline \multicolumn{5}{|l|}{ Education (ref = Illiterate) } \\
\hline Incomplete primary education & & & $-0.434^{* * *}$ & 0.272 \\
\hline Completed primary education & & & $-0.941^{* * *}$ & 0.226 \\
\hline High school graduate and above & & & $-1.437^{* * *}$ & 0.265 \\
\hline \multicolumn{5}{|l|}{ Work status (ref = No work) } \\
\hline Full- or part-time work & & & $-0.690^{* * *}$ & 0.201 \\
\hline Assisting family & & & $-0.754^{* * *}$ & 0.238 \\
\hline Home ownership (ref = no) & & & $-0.465^{* * *}$ & 0.188 \\
\hline \multicolumn{5}{|l|}{ Family background } \\
\hline \multicolumn{5}{|l|}{ Family living arrangement (ref $=$ Alone) } \\
\hline Living with family & & & $-0.534^{* * *}$ & 0.200 \\
\hline Symptom level, intercept & $3.142^{* * *}$ & 0.209 & $4.146^{* * *}$ & 0.367 \\
\hline Mean growth rate, linear & $0.182^{* *}$ & 0.031 & $0.175^{* * *}$ & 0.030 \\
\hline Mean acceleration, quadratic & $-0.004^{* * *}$ & 0.001 & $-0.004^{* *}$ & 0.001 \\
\hline Random effects & Estimate & S.E. & Estimate & S.E. \\
\hline Variance in random intercept & $4.285^{* * *}$ & 0.735 & $2.392^{* * *}$ & 0.599 \\
\hline Variance in random slope & $0.018^{* * *}$ & 0.006 & $0.017^{* * *}$ & 0.005 \\
\hline Variance in residuals & $13.297^{* * *}$ & 0.342 & $13.335^{* * *}$ & 0.318 \\
\hline
\end{tabular}

${ }^{*} p<0.05 ;{ }^{* *} p<0.01 ;{ }^{* *} p<0.001$

health, even though such participation may be varied by different types of social activities and it may also be caused by many other potentially motivating factors such as the desire to attend social functions and a search for emotional support. Our analysis also demonstrates that it is never too late to reap the psychological benefits of human interaction.

Previous studies have suggested a gender difference in the relationship between social participation and mental health status among older adults [22]. However, our analyses did not yield any gender differences in both domains of depressive symptoms. This discrepancy may be due to the relatively small female subgroup $(\mathrm{N}=51)$ that reported continuous social participation over the course of the study. In other words, the statistical power for detecting this particular relationship might be quite low. More work is needed to assess the potential gender differences in social participation and the effect of this 
Table 3 Growth curve models predicting depressive symptomatology on the lack of positive affect domain, the Taiwan Longitudinal Study on Aging (TLSA) 1989-2007

\begin{tabular}{|c|c|c|c|c|}
\hline \multirow[b]{2}{*}{ Covariates } & \multicolumn{2}{|c|}{ Model 1} & \multicolumn{2}{|c|}{ Model 2} \\
\hline & Coefficient $(\beta)$ & Standard Error & Coefficient $(\beta)$ & Standard Error \\
\hline \multicolumn{5}{|l|}{ Social participation } \\
\hline \multicolumn{5}{|l|}{ Participation before 70 (ref $=$ never participated $)$} \\
\hline Continuous participation from baseline to age $70, \beta_{01}$ & $-0.736^{* * *}$ & 0.107 & $-0.600^{* * *}$ & 0.108 \\
\hline Initiating participation from baseline to age $70, \beta_{02}$ & $-0.472^{* * *}$ & 0.104 & $-0.398^{* * *}$ & 0.102 \\
\hline Ceased participation after baseline, $\beta_{03}$ & $-0.203^{* * *}$ & 0.115 & $-0.114^{* * *}$ & 0.115 \\
\hline Dropped out before age $70, \beta_{04}$ & $-0.092^{* * *}$ & 0.124 & $-0.073^{* * *}$ & 0.123 \\
\hline \multicolumn{5}{|l|}{ Health status } \\
\hline \multicolumn{5}{|l|}{ Physical disability (ref = None) } \\
\hline 1+ functioning limitations & & & $0.321^{* * *}$ & 0.080 \\
\hline \multicolumn{5}{|l|}{ Chronic health problems (ref = None) } \\
\hline $1+$ chronic conditions & & & $-0.128^{* * *}$ & 0.099 \\
\hline \multicolumn{5}{|l|}{ Socio-demographics } \\
\hline \multicolumn{5}{|l|}{ Gender (ref = Male) } \\
\hline Female & & & $-0.250^{* * *}$ & 0.098 \\
\hline \multicolumn{5}{|l|}{ Ethnicity (ref = Fukianese) } \\
\hline Hakka & & & $-0.053^{* * *}$ & 0.106 \\
\hline Mainlander & & & $+0.012^{* * *}$ & 0.097 \\
\hline \multicolumn{5}{|l|}{ Socioeconomic position } \\
\hline \multicolumn{5}{|l|}{ Education (ref = Illiterate) } \\
\hline Incomplete primary education & & & $-0.351^{* * *}$ & 0.120 \\
\hline Completed primary education & & & $-0.502^{* * *}$ & 0.099 \\
\hline High school graduate and above & & & $-0.697^{* * *}$ & 0.116 \\
\hline \multicolumn{5}{|l|}{ Work status (ref = No work) } \\
\hline Full- or part-time work & & & $-0.117^{* * *}$ & 0.189 \\
\hline Assisting family & & & $-0.009^{* * *}$ & 0.156 \\
\hline Home ownership (ref = no) & & & $-0.132^{* * *}$ & 0.083 \\
\hline \multicolumn{5}{|l|}{ Family background } \\
\hline \multicolumn{5}{|l|}{ Family living arrangement (ref $=$ Alone) } \\
\hline Living with family & & & $-0.185^{* * *}$ & 0.088 \\
\hline Symptom level, intercept & $3.814^{* * *}$ & 0.103 & $4.443^{* * *}$ & 0.171 \\
\hline Mean growth rate, linear & $-0.172^{* * *}$ & 0.018 & $-0.173^{* * *}$ & 0.018 \\
\hline Mean acceleration, quadratic & $0.005^{* * *}$ & 0.001 & $0.005^{* * *}$ & 0.001 \\
\hline Random effects & Estimate & S.E. & Estimate & S.E. \\
\hline Variance in random intercept & $0.952^{* * *}$ & 0.196 & $0.874^{* *}$ & 0.192 \\
\hline Variance in random slope & $0.002^{* * *}$ & 0.001 & $0.002^{* *}$ & 0.001 \\
\hline Variance in residuals & $4.557^{* * *}$ & 0.106 & $4.546^{* * *}$ & 0.106 \\
\hline
\end{tabular}

${ }^{*} p<0.05 ;{ }^{* *} p<0.01 ;{ }^{* *} p<0.001$

dynamic variable on psychological distress among Taiwanese older adults [42].

Although our work provides important insights into the social aspects of mental health for older adults in non-Western countries using longitudinal data, we acknowledge that our approach has several limitations. First, the scope of this study was limited to social participation in general. As the Taiwanese place a high value on family, future research needs to specifically compare the influence of social participation through family versus community activities. Second, in order to maximize our analytic sample by minimizing the risk of the attrition over time, we focused on a sample aged from 60 to 64 years with 18 years of follow-up data, a relatively "young" and healthy group of older adults. This selected sample limits the generalizability of the results to the "youngest old," who are likely to have higher rates of social participation than members of the older cohorts due to better health, less disability, and wider social circles. Third, the TLSA data is based on self- 
reported recall of social activities and depressive symptoms, raising the issues of recall bias. Fourth, the individual controls used in the analyses are based on baseline measures. Several of these variables such as health status and family living arrangement were likely to have changed over the 18-year period of study. Analysis of the additional time-varying covariates was beyond the scope of this investigation which focused on the time-varying nature of social participation and the relationship of this focal construct with mental health. The next logical step in this line of inquiry is to investigate the role of changes in social support, health and disability status experienced by older adults in the pathway between social participation and emotional health.

\section{Conclusions}

This study extends prior research concerning the longitudinal relationship between aging and depressive symptomatology to address gaps in the empirical literature on the association between social participation and distress among older members of the Taiwanese population. Our analyses demonstrated that social participation is globally beneficial to the psychological health of older adults and that specifically, continued or initiated social activities mitigates depressive symptoms that are likely to be experienced in later life. This study also contributes to the growing interest in late-life social participation and mental health for a population that is not frequently the focus of empirical studies in mental health and aging. Public policy and healthcare interventions aiming at promoting social participation for older adults represent a promising area for maintaining good mental health among a growing segment of Taiwanese society.

\section{Note}

TLSA data are openly available and can be applied for research use by approval of the Bureau of Health Promotion at the Department of Health in Taiwan.

\section{Appendix: The 10 CES-D items used across the waves in TLSA}

Everyone has mood changes. In the past week, have you experienced the following situations or feelings? If yes, continue to ask: Does this happen to you rarely (one day in the past week), sometimes (2-3 days in the past week), often or chronically (over 4 days in the past week)?

\section{Negative affect}

1. Not interested in eating, have a poor appetite.

2. Feel that doing everything was exhausting.

3. Sleep poorly (unable to sleep soundly).

4. Feel you were in a terrible mood.
5. Feel lonely (isolated, with no companion).

6. Feel people around you weren't nice to you (unfriendly).

7. Feel anguish.

8. Unable to gather your energy to do things (Had no will to do anything).

\section{Lack of positive affect: reverse scored}

1. Feel joyful.

2. Feel that your life was going well.

\section{Acknowledgements and Funding}

The authors thank the Bureau of Health Promotion at the Department of Health in Taiwan for permission to analyze the data from the Taiwan Longitudinal Study on Aging (TLSA). Support from the National Science Council in Taiwan under grants NSC95-2412-H-006-004 and NSC97-2314-B010-047-MY3 is also gratefully acknowledged. Preliminary findings from this research were presented at the 2009 Annual Meetings of the Population America Association. The conclusions herein are those of the authors and do not represent the viewpoint of the Bureau.

\section{Author details}

'Insitute of Health and Welfare Policy, Research Center for Health and Welfare Policy, School of Medicine, National Yang-Ming University, Taipei, Taiwan, China. ${ }^{2}$ Department of Psychology, College of Science, National Taiwan University, Taipei, Taiwan, China. ${ }^{3}$ Kessler Foundation Research Center \& Department of Physical Medicine \& Rehabilitation, UMDNJ-New Jersey Medical School, USA.

\section{Authors' contributions}

CC was responsible for development of study hypotheses, data analysis, and drafting of the article. LJW contributed to developing study hypotheses and critical revision of the article. ALB contributed to critical revision of the article. All authors involved in the writing of the paper, and all approved the final submission.

\section{Competing interests}

The authors declare that they have no competing interests.

Received: 20 October 2010 Accepted: 10 May 2011

Published: 10 May 2011

\section{References}

1. Chi I, Yip PS, Chiu HF, Chou KL, Chan KS, Kwan CW, Conwell Y, Caine E: Prevalence of depression and its correlates in Hong Kong's Chinese older adults. Am J Geriatr Psychiatry 2005, 13(5):409-16.

2. Chou KL, Chi I: Prevalence and correlates of depression in Chinese oldest-old. Int I Geriatr Psychiatry 2005, 20:41-50.

3. Mehta KM, Yaffe K, Langa KM, Sands L, Whooley MA, Covinsky KE: Additive effects of cognitive function and depressive symptoms on mortality in elderly community-living adults. I Gerontol A Biol Sci Med Sci I Gerontol A Biol Sci Med Sci 2003, 58A(5):461-467.

4. Steffens DC, Otey E, Alexopoulos GS, Butters MA, Cuthbert B, Ganguli M, Geda YE, Hendrie HC, Krishnan RR, Kumar A, Lopez OL, Lyketsos CG, Mast BT, Morris JC, Norton MC, Peavy GM, Petersen RC, Reynolds CF, Salloway S, Welsh-Bohmer KA, Yesavage J: Perspectives on depression, mild cognitive impairment, and cognitive decline. Arch Gen Psychiatry 2006, 63:130-138.

5. Rowan PJ, Haas D, Campbell JA, Maclean DR, Davidson KW: Depressive symptoms have an independent, gradient risk for coronary heart disease incidence in a random, population-based sample. Ann Epidemio 2005, 15(4):316-20

6. Turner RJ, Noh S: Physical disability and depression: A longitudinal analysis. J Health Soc Behav 1998, 29:23-7.

7. Coren S, Hewitt PL: Sex differences in elderly suicide rates: some predictive factors. Aging Ment Health 1999, 3:112-119. 
8. Gottfries CG: Late-life depression. Eur Arch Psychiatry Clin Neurosci 2001, 251:57-61.

9. Kessler RC, Borges $\mathrm{G}$, Walters EE: Prevalence of and risk factors for lifetime suicide attempts in the National Comorbidity Study. Arch Gen Psychiatry 1999, 56:617-626.

10. Tsoi WF, Kua EH: Suicide following parasuicide in Singapore. Br J Psychiatry 1987, 151:543-545.

11. Glass TA, de Leon CM, Marottoli RA, Berkman LF: Population based study of social and productive activities as predictors of survival among elderly Americans. BMJ 1999, 319:478-83.

12. Hsu HC: Does social participation by the elderly reduce mortality and cognitive impairment? Aging Ment Health 2007, 11(6):699-707.

13. Jang Y, Mortimer JA, Haley WE, Graves ARB: The role of social engagement in life satisfaction: Its significance among older individuals with disease and disability. J App/ Gerontol 2004, 23:266-278.

14. Glei DA, Landau DA, Goldman N, Chuang YL, Rodriguez G, Weinstein M: Participating in social activities helps preserve cognitive function: an analysis of a longitudinal, population-based study of the elderly. Int $J$ Epidemiol 2005, 34:864-871

15. Ho SC, Woo J, Sham A, Chan SG, Yu AL: A 3-year follow-up study of social, lifestyle and health predictors of cognitive impairment in a Chinese older cohort. Int J Epidemiol 2001, 30:1389-1396.

16. Folland S: Does "community social capital" contribute to population health? Soc Sci Med 2007, 64:2342-54

17. Putnam RD, Feldstein LM, Cohen D: Better together: restoring the American community New York: Simon \& Schuster; 2003.

18. Ellison CG, George LK: Religious involvement, social ties, and social support in a southeastern community. J Sci Study of Relig 1994, 33:46-61.

19. Musick M, Wilson J: Volunteering and depression: The role of psychological and social resources in different age groups. Soc Sci Med 2003, 56:259-269.

20. Yunqing Li, Ferraro KF: Volunteering and depression in later life: Social benefit or selection processes? J Health Soc Behav 2005, 46:68-84.

21. Thoits PA, Hewitt LN: Volunteer work and well-being. J Health Soc Behav 2001, 42:115-131.

22. Sugihara $Y$, Sugisawa $H$, Shibata $H$, Harada $K$ : Productive roles, gender, and depressive symptoms: evidence from a national longitudinal study of late-middle-aged Japanese. J Gerontol B Psychol Sci Soc Sci 2008, 63(4): p227-234.

23. Pearlin LI, Schieman S, Fazio EM, Meersman SC: Stress, health, and the life course: some conceptual perspectives. J Health Soc Behav 2005, 46(2):205-219.

24. Taiwan Provincial Institute of Family Planning: 1989 Survey of Health and Living Status of the Elderly in Taiwan: Questionnaire and Survey Design Comparative Study of the Elderly in Four Asian Countries, Research Report No. 1. Issued by the Taiwan Provincial Institute of Family Planning, Population Studies Center and Institute of Gerontology, University of Michigan; 1989.

25. Taiwan Ministry of Interior: Life Expectancy - 1970-2010 Department of Statistics, Taiwan;[http://sowf.moi.gov.tw/stat/Life/lt78.htm], (accessed 10, January, 2011)

26. Radloff LS: The CES-D scale: a self-report depression scale for research in the general population. Appl Psychol Meas 1977, 1:385-401.

27. Boey KW: Cross-validation of a short form of the CES-D in Chinese elderly. Int J Geriatr Psychiatry 1999, 14(8):608-617.

28. Cheng ST, Chan AC: The Center for Epidemiologic Studies Depression Scale in older Chinese: thresholds for long and short forms. Int J Geriatr Psychiatry 2005, 20(5):465-70.

29. Chien CP, Cheng TA: Depression in Taiwan: Epidemiological survey utilizing CES-D. Seishin Shinkeigaku Zasshi 1985, 87(5):335-8.

30. Lee K-L, Ou Y-L, Chen S-H, Weng L-J: The psychometric properties of a short form of the CES-D used in the Taiwan longitudinal study on aging. J Formosa Ment Health 2009, 22(4):383-410.

31. Chiao C, Weng LJ, Botticello AL: Do older adults become more depressed with age in Taiwan? The role of social position and birth cohort. J Epidemiol Community Health 2009, 63:625-632.

32. Edwards MC, Cheavens JS, Heiy JE, Cukrowicz KC: A reexamination of the factor structure of the center for epidemiologic studies depression scale: Is a one-factor model plausible? Psychological Assessment 2010, 22(3):711-715.
33. Chiou CJ, Chen IP, Wang HH: The health status of family caregivers in Taiwan: An analysis of gender differences. Int J Geriatr Psychiatry 2005, 20:821-826.

34. Freedman VA, Crimmins E, Schoeni RF, Spillman BC, Aykan H, Kramarow E, Land K, Lubitz J, Manton K, Martin LG, Shinberg D, Waidmann T: Resolving inconsistencies in trends in old-age disability: Report from a technical working group. Demography 2004, 41(3):417-441.

35. Manton KG, Corder LS, Stallard E: Estimates of change in chronic disability and institutional incidence and prevalence rates in the U.S. elderly population from the 1982, 1984, and 1989 National Long Term Care Survey. J Gerontol B Psychol Sci Soc Sci 1993, 48(4):S153-S166.

36. Pavalko EK, Mossakowski K, Hamilton V: Does perceived discrimination affect health? Longitudinal relationships between work discrimination and women's physical and emotional health. J Health Soc Behav 2003, 44:18-33.

37. Schoeni RF, Liang J, Bennett J, Sugisawa H, Fukaya T, Kobayashi E: Trends in old-age functioning and disability in Japan, 1993-2002. Population Studies 2006, 60(1):39-53.

38. Kahn JR, Pearlin LI: Financial strain over the life course and health among older adults. J Health Soc Behav 2006, 47(1):17-31.

39. Krause N: Chronic financial strain, social support, and depressive symptoms among older adults. Psycho Aging 1987, 2(2):185-92.

40. Stata Corporation: STATA 2001 [http://www.stata.com].

41. Raudenbush SW, Bryk AS: Hierarchical linear models: Applications and data analysis methods Thousand Oaks, Calif.: Sage Publications; 2002.

42. Danigelis NL, McIntosh BR: Resources and the productive activity of elders race and gender as contexts. J Gerontol B Psychol Sci Soc Sci 1993, 48(4):S192-S203.

\section{Pre-publication history}

The pre-publication history for this paper can be accessed here:

http://www.biomedcentral.com/1471-2458/11/292/prepub

\section{doi:10.1186/1471-2458-11-292}

Cite this article as: Chiao et al.: Social participation reduces depressive symptoms among older adults: An 18-year longitudinal analysis in Taiwan. BMC Public Health 2011 11:292.

\section{Submit your next manuscript to BioMed Central and take full advantage of:}

- Convenient online submission

- Thorough peer review

- No space constraints or color figure charges

- Immediate publication on acceptance

- Inclusion in PubMed, CAS, Scopus and Google Scholar

- Research which is freely available for redistribution

Submit your manuscript at www.biomedcentral.com/submit
C Biomed Central 